\title{
Benign Melanocytoma
}

National Cancer Institute

\section{Source}

National Cancer Institute. Benign Melanocytoma. NCI Thesaurus. Code C98709.

A benign neoplasm or hamartoma composed of melanocytes. 